\title{
LA REFORMA DEL ARTÍCULO 102, APARTADO “B”, DE LA CONSTITUCIÓN POLÍTICA DE LOS ESTADOS UNIDOS MEXICANOS
}

EN PRIMER LUGAR, debemos señalar que el texto que estamos comentando no es aún una reforma constitucional, aunque sea evidente que lo será en breve plazo, hasta el momento es sólo el dictamen de reformas y adiciones aprobado por ambas cámaras del Congreso de la Unión, y que fue remitido para su correspondiente aprobación a las legislaturas de los estados, las que seguramente lo aprobarán muy pronto.

\section{ANTECEDENTES}

La instauración en México de la figura, originalmente escandinava pero hoy universal, del ombudsman, a nuestro parecer con mucho éxito, ha sido sumamente polémica entre distintos sectores de la sociedad, y muy en especial entre los profesionales del derecho. La polémica comenzó desde el momento de su creación, tanto por la vía que se utilizó para hacerlo, como por el momento y circunstancias que rodearon su creación.

Todos recordamos que la Comisión Nacional de Derechos Humanos (CNDH) fue creada como un órgano desconcentrado de la Secretaría de Gobernación, por decreto del presidente Carlos Salinas de Gortari, del 5 de junio de 1990.

En su momento fue duramente criticado que fuera creado un órgano de este tipo por decreto del presidente de la República, señalándose como negativas tres cuestiones fundamentales: la primera que no estaba dentro de sus competencias y facultades; segunda, que se estaba creando un nuevo órgano del Poder Ejecutivo que interfería con la actuación de los otros poderes, en especial del Poder Judicial (tanto federal como locales) y los ejecutivos de los estados, con lo que se atentaba contra los principios de división de poderes y del federalismo, ambos constitucionalmente 
establecidos, y, finalmente, que un órgano creado por el titular Poder Ejecutivo, quien además se arrogaba las facultades de nombrar a su titular y a los miembros de su Consejo, que tendría como función primordial vigilar a los órganos y funcionarios del propio Poder Ejecutivo, resultaba al menos un órgano ineficiente, cuando no una simple simulación. Se hacía notar especialmente que la mayoría de los ombudsman en el mundo han sido creados por el Parlamento, que designa a su titular y ante el cual se rinden los informes de la actuación del órgano.

En lo que corresponde a las circunstancias en que el órgano fue creado, se dijo que no fue más que para satisfacer los intereses políticos del presidente de la República, quien necesitaba legitimar su gobierno en los órdenes tanto interno como ante la comunidad internacional, frente a las dudas sobre la limpieza y legitimidad del proceso electoral del que surgió. Recordemos el vergonzoso episodio de la caída del sistema de cómputo que llevaba la contabilidad del proceso.

Igualmente, se dijo que en el contexto de las relaciones internacionales, siendo uno de los intereses prioritarios del presidente la celebración del Tratado de Libre Comercio con los Estados Unidos y Canadá, uno de los obstáculos que se tenían para esa inserción de nuestro país en el círculo de los países desarrollados era precisamente la catalogación de México como un Estado con una muy pobre vigencia de los derechos humanos, por lo que era necesario revertir esa información en la comunidad internacional. Como vemos, de nuevo en este aspecto se presentaba la creación de la CNDH, en tanto expresión de los intereses de la política presidencial.

Desde nuestro punto de vista, estas críticas que hemos señalado, si bien algunas son ciertas, o al menos parcialmente ciertas, con ellas se pretendió ocultar la necesidad de desarrollar en México un organismo de este tipo para lograr una mayor vigencia de los derechos humanos.

En lo que corresponde al señalamiento de que el presidente de la República no tenía facultades para crear un órgano de esas características, consideramos que efectivamente no las tenía, al menos para crear un órgano con los alcances que se le dieron al mismo, pues efectivamente significaba una injerencia en los poderes judiciales no autorizada constitucionalmente, así como una intervención en la soberanía estatal, igualmente no autorizada por la Constitución. Por supuesto que se puede dar la interpretación de que al no ser como tal el órgano creado un órgano 
de autoridad, entonces no se daba esa injerencia ilegal, sin embargo no puede negarse que en la realidad sí es un órgano que interfiere y causa molestia, y que por tanto resultaba una intromisión de un órgano del Ejecutivo federal en los otros poderes federales y locales, en violación de los principios constitucionales.

Por otra parte, en lo que se refiere al señalamiento de la dependencia y vinculación del órgano con el presidente de la República, lo que tendría como resultado su falta de autonomía (lastre que hasta la fecha viene arrastrando la CNDH, y que es uno de los motivos fundamentales de la presente reforma), debemos señalar que a primera vista eso resulta absolutamente cierto. La situación ideal hubiera sido el que el órgano fuera creado por una reforma constitucional, como después se hizo, y que su titular fuera designado por éste. Lo que hubiera significado un seguimiento más puntual de la figura escandinava.

Sin embargo, los hubiera no existen, y debemos tomar en cuenta, con la distancia que hoy nos permiten los nueve años que han pasado desde la creación de la $\mathrm{CNDH}$, tanto las peculiaridades y características de nuestros sistemas jurídico y político, así como las circunstancias que se vivían en ese momento en nuestro país. En primer lugar, si bien el ombudsman es tradicionalmente un órgano creado por y dependiente del parlamento, ese modelo corresponde a países que tienen precisamente un sistema parlamentario, donde el Poder Legislativo tiene una mayor concentración de poder político que la que puede tener en sistemas presidenciales como el nuestro. Por lo que resultaba del todo lógico, en el caso de nuestro país que la institución no se copiara literalmente, sino que se buscara adaptarla a nuestras características y circunstancias.

En razón de lo anterior, tomado en consideración que hasta hace muy poco tiempo nuestro país no sólo vivía en un sistema presidencial, sino en un "presidencialismo", esto es, en una supremacía casi absoluta de la figura del presidente de la República sobre los demás poderes, resulta consecuente que un órgano como el ombudsman, que requiere para la eficiencia de su funcionamiento el apoyo del poder político, naciera muy vinculado al órgano concentrador del poder político, en nuestro caso el presidente de la República, aunque esto no fuera la situación idónea.

Con relación a las críticas que se hicieron en su momento respecto de que la creación del órgano en mención correspondió sólo al interés del presidente de legitimar su gobierno tanto en lo interno como ante la 
comunidad internacional, creemos que pensarlo así es producto de una enorme miopía de quienes lo afirman.

No ponemos en duda que la creación de la CNDH sirvió a los intereses políticos del presidente, eso también sería miope, pero estamos convencidos de que al hacerlo el presidente respondió, a su estilo, a una intensa demanda social, y a una necesidad real de nuestro país. Muestra de ello es que la CNDH no fue el primer ombudsman creado en nuestro país, pues desde 1979 se creó en el estado de Nuevo León la Dirección para la Defensa de los Derechos Humanos, a la que siguieron, por señalar sólo algunos: en 1985 el Defensor de los Derechos Universitarios en la UNAM, en 1986 la Procuraduría para la Defensa del Indígena en Oaxaca, en 1987 la Procuraduría Social de la Montaña en Guerrero, en 1988 la Procuraduría de Protección Ciudadana en Aguascalientes, etcétera.

En sí, lo menos relevante es la intención con la que el presidente creó la $\mathrm{CNDH}$, lo que es innegable es que con su acción hizo por la vigencia de los derechos humanos más de lo que cualquier otro gobernante ha hecho en la historia de nuestro país, aunque esto pueda parecer exagerado, y aclarando que no soy salinista. En primer lugar, la acción de creación de la CNDH fue acompañada, por primera vez en la historia de México por un reconocimiento del gobierno mexicano, ya no sólo de la posibilidad de que violara derechos humanos, sino de que efectivamente los violaba, y en algunas áreas de manera constante y reiterada, como en la procuración de justicia.

Este reconocimiento resultó en un primer paso fundamental para avanzar en la vigencia de los derechos humanos, pues así como el primer paso para curar una enfermedad es diagnosticarla, igualmente no se puede avanzar en sancionar e impedir las violaciones a derechos humanos si sistemáticamente se niega incluso la posibilidad de violarlos, como venía sucediendo en nuestro país.

Por otra parte, el presidente no sólo creó el órgano, sino que también le dio su respaldo y apoyo político, posibilitando con ello, tanto su rápido crecimiento y desarrollo como el que pudieran corregirse mediante la reforma constitucional muchos de los vicios que al principio fueron señalados.

Cuando se creó la CNDH por decreto presidencial, a los pocos días su Consejo emitió su Reglamento Interno, en el cual se dieron las definiciones fundamentales sobre sus características e integración. Un punto 
importante establecido en ese Reglamento fue el de la competencia de la $\mathrm{CNDH}$, que en los términos de su artículo 3o. se concretaba en violaciones de carácter administrativo cometidas por servidores públicos, pero señalando expresamente en su artículo 4o. que no sería competente para conocer asuntos en tres casos concretos: sentencias definitivas y aspectos jurisdiccionales de fondo, en conflictos laborales, y finalmente en la calificación de elecciones.

En 1992, se terminó con la polémica sobre las facultades del presidente para crear la CNDH, y en consecuencia con las críticas a la legalidad de su actuación, pues como recordamos el 28 de enero de 1992 se publicó en el Diario Oficial de la Federación la adición de un apartado "B" al artículo 102 de la Constitución, por el cual se le daba carácter constitucional a la $\mathrm{CNDH}$, así como a los órganos correspondientes que habrían de crearse en cada uno de los estados de la República. Meses después, el 29 de junio de 1992, se publicó en el mismo Diario Oficial la Ley de la Comisión Nacional de Derechos Humanos, y lo mismo sucedió con su Reglamento Interno el 12 de noviembre del mismo año.

En esa nueva regulación de la CNDH se mantuvo en lo general la estructura institucional que venía teniendo el órgano, aunque con una regulación más completa y precisa. En lo que corresponde a las materias sobre las cuales no es competente la $\mathrm{CNDH}$, se reiteró en el segundo párrafo del apartado "B" la prohibición para que conociera de "asuntos electorales laborales y jurisdiccionales", y se añadió en el tercer párrafo una competencia para conocer de las inconformidades que se presentaran "en relación con las recomendaciones, acuerdos u omisiones de los organismos equivalentes de los estados". La mismas incompetencias se desarrollaron en el artículo 21 de la Ley de la CNDH, añadiendo que no puede resolver consultas sobre interpretación de disposiciones legales o constitucionales, es decir, le negó la facultad consultiva.

\section{LA NECESIDAD DE LA REFORMA}

En términos muy generales, podemos afirmar que desde la reforma constitucional, paulatinamente de han venido desarrollando las estructuras de la CNDH y de las correspondientes a los estados, con bastante éxito en sus actuaciones cotidianas. Sin embargo, a pesar de que la reforma constitucional se dio desde hace ya siete años, aún hay falta de 
conocimiento sobre el órgano y su funcionamiento no sólo entre la ciudadanía, sino por desgracia también entre la autoridad.

Es con base en ese desconocimiento que se han venido dando las principales quejas e incluso ataques contra la institución, sirviendo en ocasiones de excusa para la ineficacia de la autoridad, como sucede en el caso de la seguridad y la procuración de justicia, tema en el que se afirma con absoluto descaro que los organismos de defensa de derechos humanos son defensores de los delincuentes y obstaculizan su persecusión y sanción. Es evidente que esto no es más que una excusa, pues los ombudsman tienen que actuar en el marco de la legalidad, y en todo caso el obstáculo lo constituirían las propias normas jurídicas y no los órganos que buscan su aplicación, pues de ser así lo mismo podría decirse de los jueces.

Tres temas fundamentales han impulsado la presentación por parte de los distintos partidos políticos de iniciativas de reformas en torno de la $\mathrm{CNDH}$, cuyo resultado es la reforma que comentamos: la autonomía de la Comisión, la intención de ampliar su competencia en las materias en que actualmente no es competente $\mathrm{y}$, finalmente, dar mayor eficacia a sus recomendaciones.

\section{LA REFORMA}

El motivo fundamental de la reforma, en términos del mismo proyecto de decreto aprobado por la Cámara de Diputados, es "fortalecer la autonomía y ampliar las funciones de la Comisión Nacional de Derechos Humanos a efecto de incrementar la eficacia de sus resoluciones y recomendaciones".

La reforma propuesta en la que el texto del apartado "B" constará ahora de ocho párrafos, se concreta en lo siguiente: el actual primer párrafo del apartado "B" se desdobla ahora en dos párrafos, dedicando el segundo a lo que es la última parte del actual, respecto de las resoluciones que emitirán, con el único cambio en la redacción de que se elimina el término "autónomas" respecto de las recomendaciones. Lo anterior corresponde a que en lo que será un nuevo cuarto párrafo se desarrolla el tema de la autonomía del órgano.

En lo que corresponde al primer párrafo sólo hay dos cambios con respecto del texto vigente, el primero es que ahora se habla de los dere- 
chos que "ampara" el orden jurídico mexicano, y no que "otorga", como dice el texto actual. En este caso el cambio es feliz, ya que corresponde más a lo señalado por la teoría de los derechos humanos, donde el papel del Estado respecto de ellos es reconocerlos y ampararlos o garantizarlos.

El otro cambio tiene mayor importancia práctica, ya que el texto actual habla de que no podrá conocer de los actos del "Poder Judicial de la Federación", y en el texto propuesto se elimina "de la Federación", con lo que la incompetencia se extiende a los actos de los poderes judiciales locales, y si bien puede ser discutible la conveniencia o no de este cambio, lo que es evidente es que es incongruente con la intención expresada para realizar la reforma que, entre otras, era "ampliar sus funciones", cuando en este caso evidentemente se restringen.

Como tercer párrafo se reproduce el actual segundo, que corresponde a los casos de incompetencia, sin cambio alguno.

En el nuevo cuarto párrafo se señala expresamente que la $\mathrm{CNDH}$ "contará con autonomía de gestión y presupuestaria, personalidad jurídica y patrimonio propios". Características que tendrán que desarrollarse en la nueva ley de la CNDH que al efecto habrá de expedirse a la brevedad. El nuevo párrafo cuarto se refiere al Consejo de la $\mathrm{CNDH}$, que ahora se denomina "Consejo Consultivo", que continuará integrado por diez miembros, pero que ya no serán designados por el titular del Ejecutivo con ratificación del Senado, sino sólo por el Senado con el voto de dos terceras partes de sus miembros, o en sus recesos de la Comisión Permanente, con el mismo voto calificado, todo de acuerdo con el procedimiento que establezca la ley. Se establece además que anualmente serán sustituidos los dos miembros más antiguos, salvo que fueran propuestos para un nuevo periodo.

Es de señalarse que la denominación de Consejo Consultivo, no corresponde con las actuales funciones del Consejo, ya que algunas de ellas no son consultivas sino de autoridad, $v$. $g r$., las correspondientes a las fracciones I, II y III del artículo 19 de la vigente Ley de la CNDH, que se refieren a establecer los lineamientos generales de actuación de la $\mathrm{CNDH}$, a aprobar su reglamento interno y las demás normas de carácter interno.

El propuesto sexto párrafo se refiere a la designación del presidente de la CNDH, que será también del Consejo, que se realizará en los mismos términos que la de los consejeros. Se establece que durará en su 
cargo cinco años, uno más que en la Ley actual, y podrá reelegirse, además de que sólo podrá ser removido en caso de que incurra en responsabilidad en los términos del título IV de la Constitución; lo que nos hace pensar si no será necesaria una reforma a ese título para precisar sus responsabilidades.

En el sexto párrafo se establece que el presidente de la CNDH rendirá su informe anual a los poderes de la Unión, compareciendo ante las cámaras. Es un hecho que la próxima ley habrá de precisar la forma en que se rendirá el informe y las formalidades del mismo.

En el octavo párrafo transcribe literalmente el actual tercer párrafo del apartado "B", con el único cambio de que no habla de "organismos equivalentes de los estados", sino de las entidades federativas, para incluir ahí a la Comisión del Distrito Federal.

En los artículos transitorios se establece que los actuales miembros del Consejo continuarán en su cargo y podrán ser propuestos para un nuevo periodo (transitorio tercero); en cambio, respecto del presidente de la $\mathrm{CNDH}$, el transitorio cuarto prevé que el Senado deberá nombrarlo en un plazo máximo de sesenta días después de la entrada en vigor de la reforma, para lo cual deberá realizar "una amplia auscultación entre las organizaciones sociales representativas de los distintos sectores de la sociedad, así como entre los organismos públicos y privados promotores o defensores de los derechos humanos". Como resultado de la auscultación el Senado podrá ratificar a la actual presidenta o en su caso formular una terna de candidatos de la que elegirá al nuevo presidente.

\section{COMENTARIO FINAL}

Como hemos visto, los cambios más importantes que se darán en la $\mathrm{CNDH}$ como producto de la reforma inciden en su autonomía, la que se establece expresamente en sus distintos aspectos, y lo que redundará sin duda en un trabajo mejor recibido por la sociedad. También respecto de la autonomía está el que tanto el presidente como los miembros del Consejo serán ahora nombrados exclusivamente por el Senado, sin la intervención del presidente de la República. Si bien esa fórmula para la designación es sin duda más acorde con las características y funcionamiento del ombudsman, dado nuestro sistema presidencial, el Senado habrá de tener cuidado en hacer una buena selección del nuevo titular, de manera 
que pueda contar también con el apoyo político del presidente de la República.

Tal vez cause decepción entre algunos que no se hayan eliminado las llamadas incompetencias de la CNDH en materias electorales, laborales y jurisdiccionales; sin embargo debe entenderse que dotar a la Comisión de competencia en esas materias no es viable por la misma naturaleza del órgano, pues en lo que corresponde a la materia electoral se han desarrollado medios y mecanismos específicos para la defensa de los derechos políticos, por lo que hacer participar en esos temas a la CNDH sólo llevaría a su fácil politización y a su consecuente descalificación por dicha causa.

En lo que corresponde a la materia laboral, la $\mathrm{CNDH}$ no puede conocer porque los conflictos laborales, o bien son conflictos entre particulares (patrón-trabajador), o bien son asuntos que están subiudice conociéndose en las juntas de Conciliación y Arbitraje, por lo materialmente son asuntos jurisdiccionales sobre los que no puede conocer, y son impugnables precisamente por la vía del amparo. Ahora bien, esta limitante a la competencia de la Comisión no debe extenderse a actos administrativos en temas laborales, pues éstos no tienen por qué no ser conocidos por la Comisión, por ejemplo el registro de un sindicato.

En lo que corresponde a la materia jurisdiccional, la $\mathrm{CNDH}$ no puede conocer de esos asuntos dado que si lo hiciera estaría constituyéndose en un suprapoder judicial, o sustituyendo al propio Poder Judicial, lo que resulta absurdo. Por otra parte, la actuación judicial está sujeta al debido proceso legal y a un sistema probatorio también legalmente establecido, que le permiten arribar a una verdad legal, probada en autos, que es garantía de seguridad jurídica para los particulares. En cambio los ombudsman en sus actuaciones no están ceñidos por el debido proceso ni por un sistema probatorio, de hecho sus resoluciones se fundan en convicciones (a las que por supuesto no llegan de manera arbitraria, sino buscando acercarse el mayor número de pruebas que den valor a su convicción), que el propio poder judicial ha establecido no pueden constituir prueba dentro de un proceso; lo cual es congruente con su carácter de un órgano que no emite resoluciones vinculatorias, y que debe ser considerado no como autoridad sino como un coadyuvante de la autoridad.

De acuerdo con lo anterior es también claro por qué las resoluciones de los ombudsman no pueden tener carácter vinculante, pues si se emi- 
tieran como hasta ahora, resultarían violatorias de la garantía de seguridad jurídica; y si se le dotara de un procedimiento legal y un sistema probatorio, lo que estaríamos haciendo sería crear un Poder Judicial paralelo.

No puede negarse que hasta hoy la actuación, en términos generales, de las comisiones de derechos humanos en nuestro país ha presentado problemas y en ocasiones ha sido deficiente; sin embargo, si hiciéramos un balance estoy seguro de que tendríamos que concluir que gracias a la creación, existencia y funcionamiento de estos órganos hemos avanzado en la vigencia cotidiana de los derechos humanos, así como en la formación de una cultura de derechos humanos cada vez más presente en la sociedad, que a su vez cada día participa más en lo que finalmente no es sino la lucha de la defensa de la dignidad de los seres humanos. No nos queda sino esperar que esta reforma tenga efectos positivos para el desarrollo de nuestros peculiares ombudsman mexicanos, para lo cual será muy importante el desarrollo que se haga en las leyes que habrán de expedirse tanto a nivel federal como local.

Víctor M. MARTíNEZ BULLÉ GOYRI 